Article

\title{
Denture Acrylic Resin Material with Antibacterial and Protein-Repelling Properties for the Prevention of Denture Stomatitis
}

\author{
Salwa Omar Bajunaid ${ }^{1, *}$, Bashayer H. Baras ${ }^{2}$, Michael D. Weir ${ }^{3}$ and Hockin H. K. Xu ${ }^{3}$ \\ 1 Department of Prosthetic Sciences, College of Dentistry, King Saud University, Riyadh 60169-15, Saudi Arabia \\ 2 Department of Restorative Dental Sciences, College of Dentistry, King Saud University, \\ Riyadh 60169-15, Saudi Arabia; Bbaras@ksu.edu.sa \\ 3 Department of Advanced Oral Sciences and Therapeutics, School of Dentistry, University of Maryland, \\ Baltimore, MD 21201, USA; michael.weir@umaryland.edu (M.D.W.); hxu2@umaryland.edu (H.H.K.X.) \\ * Correspondence: sbajunaid@ksu.edu.sa; Tel.: +96-6590-0287-84
}

check for updates

Citation: Bajunaid, S.O.; Baras, B.H.; Weir, M.D.; Xu, H.H.K. Denture Acrylic Resin Material with Antibacterial and Protein-Repelling Properties for the Prevention of Denture Stomatitis. Polymers 2022, 14, 230. https://doi.org/10.3390/ polym 14020230

Academic Editors: Haw-Ming Huang and Ana María Díez-Pascual

Received: 9 December 2021

Accepted: 4 January 2022

Published: 7 January 2022

Publisher's Note: MDPI stays neutral with regard to jurisdictional claims in published maps and institutional affiliations.

Copyright: (C) 2022 by the authors. Licensee MDPI, Basel, Switzerland. This article is an open access article distributed under the terms and conditions of the Creative Commons Attribution (CC BY) license (https:// creativecommons.org/licenses/by/ $4.0 /)$.

\begin{abstract}
Denture stomatitis is a multifactorial pathological condition of the oral mucosa that affects up to $72 \%$ of denture wearers. It is commonly seen on the palatal mucosa and characterized by erythema on the oral mucosa that are in contact with the denture surface. The aim of this study was to incorporate 2-methacryloyloxyethyl phosphorylcholine (MPC) and dimethylaminohexadecyl methacrylate (DMAHDM) into a high impact polymethylmethacrylate heat-cured denture base acrylic resin as a potential treatment for denture stomatitis. We used a comparative study design to examine the effect of incorporating MPC as a protein repellent agent and DMAHDM as an antifungal agent to prevent the adherence of Candida albicans to the denture base material. The dual incorporation of MPC and DMAHDM reduced C. albicans biofilm colony-forming unit by two orders of magnitude when compared to the control group devoid of the bioactive agents. Although the addition of MPC and DMAHDM alone or in combination significantly reduced the flexural strength of the material, they showed reduced roughness values when compared to control groups. This new denture acrylic resin provides the benefit of enhancing C. albicans biofilm elimination through dual mechanisms of action, which could potentially reduce the prevalence of denture stomatitis.
\end{abstract}

Keywords: antifungal; antimicrobial; Candida albicans; denture stomatitis; flexural strength; surface roughness

\section{Introduction}

Although microbiota of different microorganisms habitate in the oral cavity to protect the human body against infectious diseases [1], certain circumstances can favor the development of oral infections; these include immunodeficiency, malnutrition, poor oral hygiene and use of an ill-fitting removable dental prosthesis [2].

Denture stomatitis (DS) is a chronic oral fungal infection (candidiasis) characterized by erythema of the mucosa underlying the removable denture surface; usually the palatal mucosa of complete denture wearers [3]. It affects up to $72 \%$ of denture wearers and has been frequently associated with colonization of microbial biofilms on the denture acrylic base and denture-bearing mucosa. Candida albicans (C. albicans) biofilms have been commonly observed on denture surfaces and were attributed to the development of denture stomatitis [4].

A removable acrylic resin denture should exhibit adequate physical, mechanical, and esthetic properties; however, the resinous nature of these materials renders them susceptible to microbial adhesion and growth, leading to denture stomatitis [5]. Local factors such as an ill-fitting dentures, rough or cracked denture surfaces, allergic reaction, poor salivary flow and the presence of candida in the mucosa facilitate the adherence and proliferation of Candida species on the surface of the denture base [6]. 
Different therapeutic strategies have been implemented for the prevention or treatment of denture stomatitis, ranging from the use of denture disinfectants and cleansers, to the administration of oral and systemic antifungal medications. Due to their toxic side effects, however, these approaches have become less frequently used [7]. Recent approaches such as the incorporation of antimicrobial agents into denture cleansers, denture acrylic resins and denture relining materials have been developed. Polymeric antifungal agents such as polymeric biocides, biocide-releasing polymers (nano-sized metal oxides) and biocidal surface coatings are commonly added to denture resin materials and have shown promising results against candida biofilms $[8,9]$.

Efforts have also been made to modify the surface of the denture acrylic resin in order to prevent $C$. albicans attachment and biofilm proliferation. These modifications include the incorporation of hydrophilic agents such as 2-octyl cyanoacrylate, silane-silicon dioxide $\left(\mathrm{SiO}_{2}\right)$, and zwitterion, which produce their action by increasing the surface hydrophilicity of the denture acrylic resin and subsequently acts as a surface repellent of C. albicans [10]. 2-methacryloyloxyethyl phosphorylcholine (MPC) is another hydrophilic methacrylate with a phospholipid polar group that has shown potent protein-repelling properties when incorporated into denture acrylic resin [11]. MPC has been incorporated into a wide range of dental materials such as dental composites, adhesives, cements, and root canal sealers and shown significantly reduced protein adsorption and microbial adhesion [12-14].

Quaternary ammonium methacrylates (QAMs) have recently been incorporated into resinous materials to combat oral pathogens, which become immobilized within the resin matrix and do not leach out, thus producing long-term contact killing properties [15]. The positively charged QAMs interact with the negatively charged cell membrane of the pathogen, producing an electrical imbalance that increases the intercellular osmotic pressure and causes the cell to burst $[13,14]$. A recent QAM with an alkyl chain length (CL) of 16-dimethylaminohexadecyl methacrylate (DMAHDM) was incorporated into various dental materials [16-18]. The long alkyl chain is able to physically pierce the microbial cellular membrane, adding to the microbial potency of the QAM [18]. When DMAHDM was incorporated into dental composites and adhesives it was able to significantly reduce biofilm CFU counts, metabolic activity and the percentage of live bacteria $[15,19]$.

To the best knowledge of the authors, the synergistic effect of MPC as a proteinrepelling agent to prevent $C$. albicans adhesion and proliferation and of DMAHDM as a contact-killing antimicrobial agent to produce long-acting antimicrobial effects has not previously been tested on denture acrylic resin materials. Thus, the present study aimed to incorporate MPC and DMAHDM into a heat-cured polymethylmethacrylate denture base acrylic resin as a potential treatment for denture stomatitis. Two hypotheses were tested: (1) that the addition of MPC and DMAHDM into the acrylic resin would greatly reduce the number of colony-forming units (CFU) compared to the control group; and (2) that incorporating MPC and DMAHDM into the acrylic resin would not jeopardize the flexural strength and surface roughness properties.

\section{Materials and Methods}

A heat-cured acrylic resin denture base (Lucitone 199, Dentsply International Inc., Charlotte, NC, USA) was used as the carrier for the protein-repellent monomer 2-methacryloyloxyethyl phosphorylcholine (MPC) and the antifungal agent dimethylaminododecyl methacrylate (DMAHDM). We used a comparative study design to examine the effect of incorporating MPC as a protein-repellent agent and DMAHDM as an antifungal agent to prevent the adherence of $C$. albicans to the denture base material.

\subsection{Synthesis and Incorporation of Bioactive Agents}

DMAHDM was synthesized through a Menschutkin reaction where a tertiary amine group was reacted with an organohalide to be converted into a quaternary ammonium salt. The reaction was conducted by combining $10 \mathrm{mmol}$ of 2-(dimethylamino) ethyl methacrylate (DMAEMA, Sigma-Aldrich, St. Louis, MO, USA) and $10 \mathrm{mmol}$ of 1-bromohexadecane 
(BHD, TCI America, Portland, OR, USA) with $3 \mathrm{~g}$ of ethanol in a $20 \mathrm{~mL}$ scintillation vial. The vial was then stirred for $24 \mathrm{~h}$ at $70{ }^{\circ} \mathrm{C}$. The solvent was left to evaporate, yielding DMAHDM as a clear, colorless and viscous liquid [20]. MPC was purchased from SigmaAldrich (Sigma-Aldrich, St. Louis, MO, USA).

Four groups were formulated and investigated as shown in Table 1.

Table 1. Description of different groups investigated.

\begin{tabular}{cc}
\hline Group & Description \\
\hline Group 1 (Control Group) & Lucitone acrylic resin + 0\% MPC + 0\% DMAHDM \\
Group 2 & Lucitone acrylic resin + 3\% MPC \\
Group 3 & Lucitone acrylic resin + 3\% DMAHDM \\
Group 4 & Lucitone acrylic resin + 3\% DMAHDM + 3\% MPC \\
\hline
\end{tabular}

An acrylic resin group with $0 \%$ MPC and $0 \%$ DMAHDM was used as the control group for comparison.

\subsection{Flexural Strength and Modulus of Elasticity}

Samples of each group were made by pouring the mixed materials into a $2 \mathrm{~mm} \times 2 \mathrm{~mm}$ $\times 25 \mathrm{~mm}$ stainless steel mold. The samples were then placed in water at a temperature of $163 \pm 2{ }^{\circ} \mathrm{F}\left(73 \pm 1{ }^{\circ} \mathrm{C}\right)$ for $1.5 \mathrm{~h}$ followed by $0.5 \mathrm{~h}$ in boiling water. The flexural strength of the acrylic resin was measured using a computer-controlled Universal Testing Machine (5500 R, MTS, Cary, NC, USA). A three-point flexural test was conducted with a 15-mm span at a cross head speed of $1 \mathrm{~mm} / \mathrm{min}$. The flexural strength was calculated using the formula $S=3 P \max L /\left(2 b h^{2}\right)$, where $P \max$ is the maximum load on the load-displacement curve, $L$ is the flexure span, $b$ is the specimen width, and $h$ is the specimen thickness. Modulus of elasticity was determined by the formula $E=(P / d)\left(L^{3} /\left[4 b h^{3}\right]\right)$, where load $(P)$ divided by displacement $(d)$ is the slope in the linear elastic region of the load-displacement curve.

\subsection{Surface Roughness}

Samples of each group were made by pouring the mixed materials into a $10 \mathrm{~mm} \times 2 \mathrm{~mm}$ circular mold held between two metal plates. The disks were then placed in water at a temperature of $163 \pm 2{ }^{\circ} \mathrm{F}\left(73 \pm 1^{\circ} \mathrm{C}\right)$ for $1.5 \mathrm{~h}$ followed by $0.5 \mathrm{~h}$ in boiling water, as per manufacturer instructions. For surface roughness measurements, an AFM (Atomic Force Microscopy, 5500SPM, Agilent, AZoNetwork UK Ltd., Manchester, UK) was used at high resolution with a sharp silicon tip $(0.5 \mathrm{~N} / \mathrm{m})$ in tapping mode. The surface topography of the treated acrylic resin disk was obtained over an area of $1100 \mu \mathrm{m} \times 10 \mu \mathrm{m}$, and four readings were taken for each sample. Systemic software (SPIWIN 2.0, NSK, Tokyo, Japan) provided the surface roughness of the specimens, and data on the Ra of all groups were obtained and compared.

\subsection{Colony-Forming Unit Counts}

Acrylic resin disks for antifungal experiments were made by pouring the mixed material of each group of samples into $10 \mathrm{~mm} \times 2 \mathrm{~mm}$ circular molds held between two metal plates. The disks were then placed in water at a temperature of $163 \pm 2{ }^{\circ} \mathrm{F}$ $\left(73 \pm 1^{\circ} \mathrm{C}\right)$ for $1.5 \mathrm{~h}$, followed by $0.5 \mathrm{~h}$ in boiling water. All disks were sterilized using Gamma irradiation (25 $\mu$ Grey). Candida albicans (ATCC 10231) was reactivated from the original culture in brain heart infusion (BHI) broth (Sigma-Aldrich) supplemented with $0.5 \%$ glucose, which was used as the growth medium. First, $25 \mu \mathrm{L}$ from the $C$. albicans stock culture was added into $10 \mathrm{~mL}$ of the glucose-supplemented BHI media and incubated for $24 \mathrm{~h}$ at $37{ }^{\circ} \mathrm{C}$ with $5 \% \mathrm{CO}_{2}$. After $24 \mathrm{~h}, 1 \mathrm{~mL}$ from the $\mathrm{C}$. albicans inoculum was added into $19 \mathrm{~mL}$ glucose-supplemented BHI and vortexed. Experimental acrylic resin disks were placed in a 24 -well plate where $1.5 \mathrm{~mL}$ of the inoculum was added. All samples were incubated at $5 \% \mathrm{CO}_{2}$ and $37{ }^{\circ} \mathrm{C}$ for $24 \mathrm{~h}$. Next, the disks were transferred into a new 24-well plate filled with $1.5 \mathrm{~mL}$ of fresh $\mathrm{BHI}$ media and incubated for an additional $24 \mathrm{~h}$. This two-day biofilm formation allowed for the creation of a relatively mature C. albicans biofilm on the acrylic resin disks. The acrylic disks were then transferred to a new 24-well 
plate filled with phosphate-buffered solution (PBS) and the biofilms formed on the acrylic disks were harvested via scraping. The PBS biofilm suspension was then serially diluted and plated onto BHI agar plates, which were incubated for $24 \mathrm{~h}$ at $37^{\circ} \mathrm{C}$ in $5 \% \mathrm{CO}_{2}$. The number of colony-forming units was counted using a CFU plate reader (Reichert, Depew, NY, USA) and used along with their dilution factor to determine the CFU counts (Figure 1).

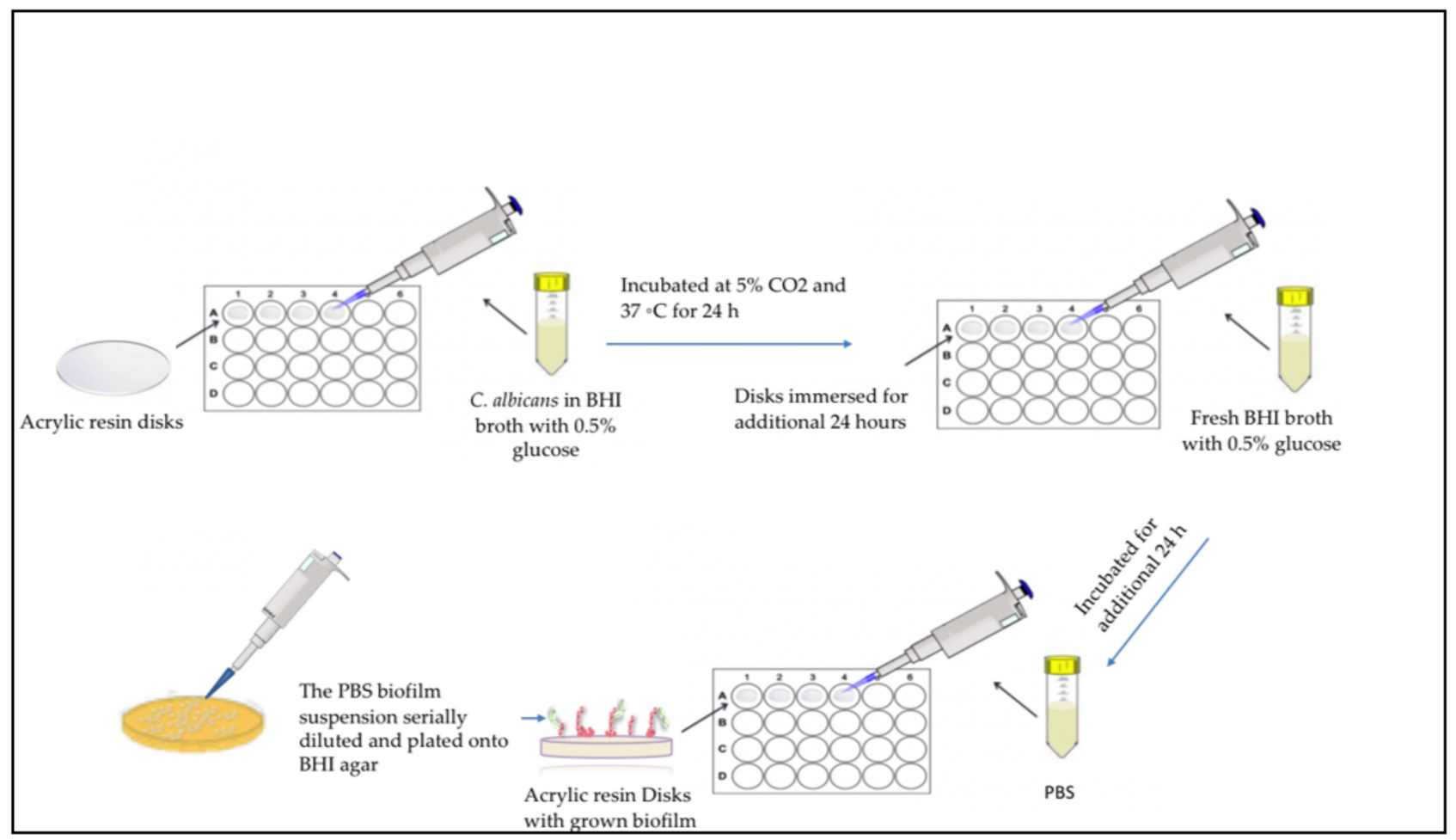

Figure 1. Biofilm growth on acrylic resin disks and antifungal colony-forming unit count experiment.

\subsection{Statistical Analysis}

Statistical analysis was performed using IBM SPSS statistics 20 at $\alpha=0.05$. One-way analysis of variance (ANOVA) with Tukey's multiple comparison test was utilized to determine the mean differences between the groups.

\section{Results}

The Lucitone acrylic resin flexural strength results are plotted in Figure 2 (mean $\pm \mathrm{sd}$; $n=6)$. The addition of MPC at $3 \%$ did not significantly influence the flexural strength of the material $(p>0.05)$. However, the addition of 3\% DMAHDM alone or in combination with MPC significantly reduced the flexural strength of the material when compared to groups without DMAHDM $(p<0.05)$.

The modulus of elasticity results are plotted in Figure 3 (mean $\pm \mathrm{sd} ; n=6$ ). The addition of MPC at 3\% did not significantly influence the modulus of elasticity of the material $(p>0.05)$. The addition of 3\% DMAHDM alone resulted in modulus of elasticity values that were not significantly different from groups devoid of DMAHDM $(p>0.05)$. Combining DMAHDM with MPC, however, resulted in a significant reduction of the modulus of elasticity when compared to groups with $0 \%$ DMAHDM $(p<0.05)$. 


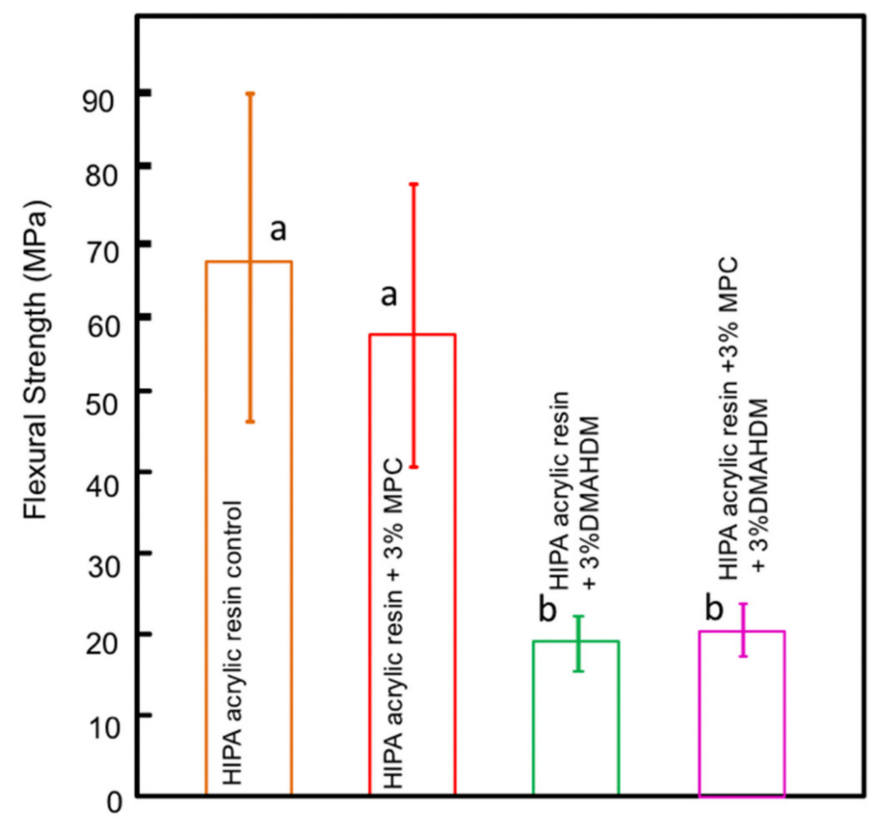

Figure 2. Flexural strength of the acrylic resin; similar letters indicate statistical similarity (Tukey's test, $p<0.05)$.

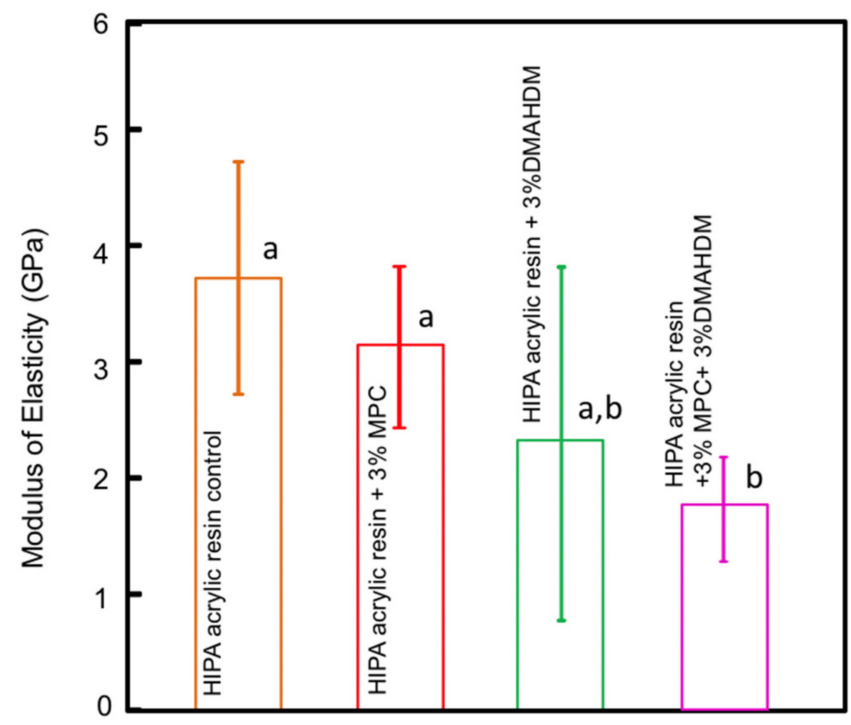

Figure 3. Acrylic resin modulus of elasticity; similar letters indicate statistical similarity (Tukey's test, $p<0.05)$.

Figure 4 shows the surface roughness $(\mathrm{Ra})$ results of the experimental acrylic resin groups (mean $\pm \mathrm{sd} ; n=6$ ). The addition of $3 \% \mathrm{MPC}$ did not seem to significantly influence the roughness properties of the material when compared to the acrylic resin with $0 \%$ MPC $(p>0.05)$. The addition of DMAHDM alone or in combination with MPC seemed to significantly improve the surface roughness properties compared to the control group $(p<0.05)$. 


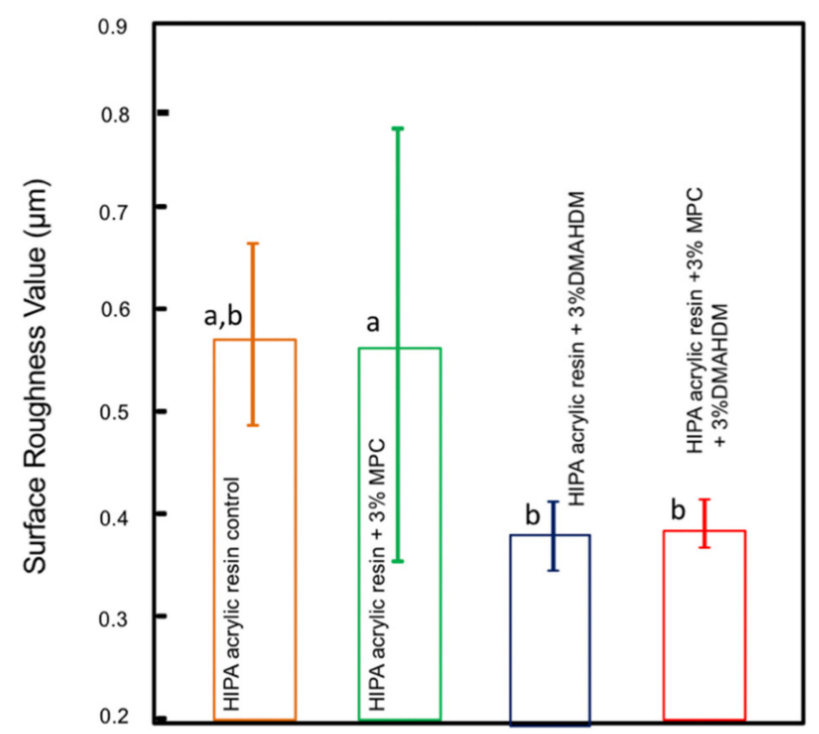

Figure 4. Surface roughness of acrylic resin; similar letters indicate statistical similarity (Tukey's test, $p<0.05)$.

CFU counts of two-day biofilms on Lucitone acrylic resin disks are plotted in Figure 5 (mean $\pm \mathrm{sd} ; n=6$ ). The addition of DMAHDM alone reduced CFU counts by about $1 \mathrm{log}$ when compared to the control group. The results, however, were not statistically different $(p>0.05)$. Combining DMAHDM and MPC resulted in a biofilm CFU reduction of approximately 2 logs compared to the control group with $0 \%$ MPC and 0\% DMAHDM. However, this difference was not statistically different either $(p>0.05)$.

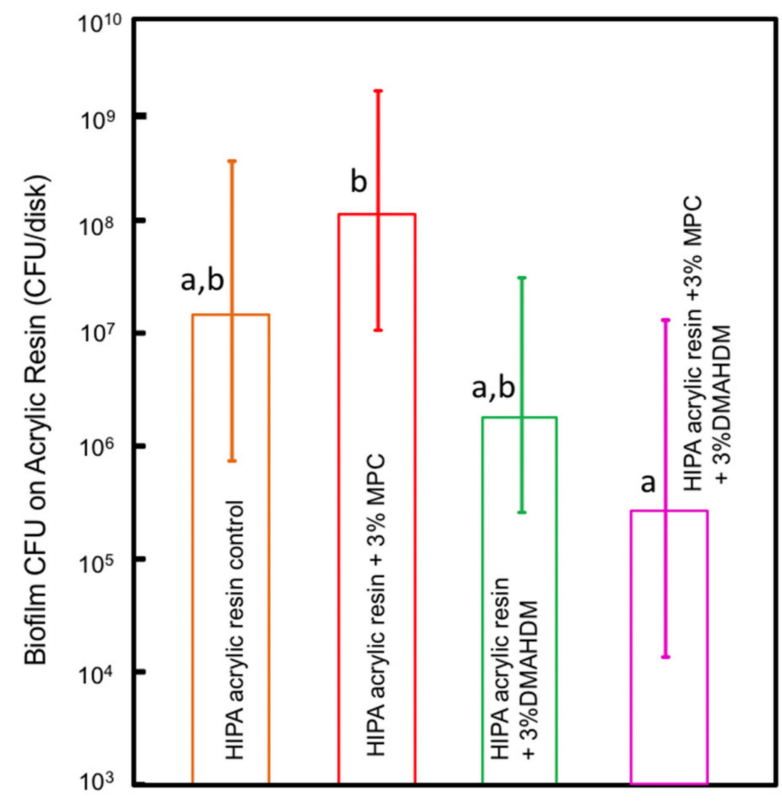

Figure 5. Acrylic resin biofilm colony-forming units; similar letters indicate statistical similarity (Tukey's test, $p<0.05$ ).

\section{Discussion}

Denture stomatitis is one of the most commonly encountered oral infections among denture wearers [4]. It is characterized by erythematous lesions on the oral mucosa, especially the palatal denture-bearing mucosa, due to their intimate contact with the removable denture [21]. Its presence plays a huge role in patients' ability to practice everyday maneuvers such as pronunciation and proper mastication of food, which can 
lead to nutritional deprivation [22]. Factors such as poor oral hygiene, long duration of denture use, poor salivary flow, and certain systemic diseases have all been associated with denture stomatitis. The colonization of $C$. albicans biofilms, however, has been strongly characterized as a causative factor of this fungal infection $[4,23]$.

As the world is facing the Severe acute respiratory syndrome Coronavirus-2 (SARSCoV-2) pandemic, it is important to differentiate between oral symptoms related to infection by SARS-CoV-2 and other microbial oral infections among removable denture wearers. Most of the symptoms related to COVID-19 infection are presumably due to immunosuppression and predisposition to opportunistic infections such as candidiasis [24]. A survey study conducted to assess facial and oral manifestations as adverse effects of COVID-19 vaccination concluded that oral and facial symptoms were reported by only $3.1 \%$ and $5.4 \%$ of the respondents, respectively. Among the oral manifestations, a burning sensation and oral aphthous-like lesions were the most frequent, which may be confused with symptoms of oral manifestations of denture stomatitis [24]. Another survey was performed on 665 Egyptian patients who were confirmed to be COVID-19-positive; the survey reported $71.7 \%$ of COVID-19 patients to have some oral manifestations, including oral or dental pain (23\%) and ulcerations (20.4\%) (2). The results of the survey emphasize the significance of thorough history-taking and dental examination of patients with communicable diseases [25].

Developing acrylic resin denture materials that can inhibit the colonization of $C$. albicans biofilms can potentially prevent the development of denture stomatitis, and is thus highly desirable. The present study aimed to develop a denture acrylic resin material with dual strategies to prevent $C$. albicans-induced denture stomatitis. The Lucitone acrylic resin contained a protein-repelling agent (MPC) to prevent $C$. albicans adhesion and a contact-killing antimicrobial agent (DMAHDM) to produce long-acting antimicrobial effects, enhance the longevity of removable dentures, and improve patients' quality of life.

Deposition of salivary proteins on material surfaces has been reported to promote microbial attachment and proliferation [26]. Surfaces with hydrophilic characteristics have demonstrated their ability to repel proteins, thus limiting microbial adhesion [27]. 2-methacryloyloxyethyl phosphorylcholine (MPC) is a hydrophilic polymer with an abundance of free water around the phosphorylcholine group, which helps in the repellence and detachment of proteins $[11,28,29]$.

Quaternary ammonium methacrylates (QAMs) are contact-killing polymers. Their mechanism of action occurs when the positivley charged QAMs come into contact with the negatively charged cell membrane, which results in an electrical imbalance between the two charges. As a result, the microbial cell expands due to an increase in its osmotic pressure and eventually ruptures, leading to cytoplasmic leakage [15]. Furthermore, the alkyl chain length (CL) of QAMs can influence its antimicrobial potency where longer alkyl chains can physically penetrate the microbial cell membrane, resulting in the disruption of its continuity. In a study by Li et al., QAMs were synthesized with CL ranging from 3 to 18 which were incorporated into Scotchbond Multi-Purpose (SBMP) bonding agent. Increasing the CL from 3 to 16 decreased the minimum inhibitory concentration and minimum bactericidal concentration by five orders of magnitude. SBMP with QAM of CL 16 (DMAHDM) achieved the lowest CFU counts, which were 4 logs lower than SBMP control [19].

Combining MPC (as a protein repellent) with DMAHDM (as an antimicrobial contactkilling agent) can be of special importance. We speculate that in order for DMAHDM to produce its action, it must come into intimate contact with the microbial cell. The presence of proteins on top of the surface of the material may hinder the action of DMAHDM. Hence, MPC and DMAHDM appear to work synergistically. As MPC repels salivary proteins from the surface of the material, DMAHDM is able to exert its potent contact-killing properties. This synergistic effect can be seen in the CFU results of the present study, as combining MPC and DMAHDM together produced the lowest CFU counts among all groups. 
The results of the present study show that the dual incorporation of MPC and DMAHDM reduced C. albicans biofilm colony forming units (CFU) by two orders of magnitude when compared to the control group devoid of the bioactive agents. These results are in agreement with the results of Bajunaid et al., who found that denture acrylic resin containing higher concentrations of MPC significantly reduced C. albicans CFU without compromising the surface roughness of the material [11]. Another study by Li Cao et al. suggested that PMMA resin with $3 \% \mathrm{MPC}+1.5 \%$ DMAHDM led to a greater reduction in biofilm growth than using MPC or DMAHDM alone $(p<0.05)$ [30]. Moreover, Campos et al. found similar antimicrobial properties of DMAHDM and chlorhexidine diacetate in self-cured acrylic resin [31].

The effect of incorporating DMAHDM and MPC, either separately or combined, into different dental materials has been thoroughly investigated, and the literature showed promising results. Baras et al. suggested that the incorporation of DMAHDM at 5\% into a root canal sealer resulted in a decrease in E. faecalis biofilm CFU by more than four orders of magnitude and a reduction in polysaccharide biofilm production when compared to control groups [32]. Wang et al. combined MPC and DMAHDM into a root canal sealer, and their results showed that the combination effect demonstrated much greater killing efficacy than that achieved by either DMAHDM or MPC alone [17]. Another study by Zhou et al. showed the ability of DMAHDM to reduce biofilm thickness and live biofilm volume when incorporated into a bonding agent [18]. Zhang et al. found that when MPC was incorporated into an orthodontic cement, the developed cement adsorbed only 1/10 of the amount of protein of a commercial control group [15].

While the novel denture acrylic resin with antimicrobial properties in the present study showed promising results, these new resins are required to be biocompatible and non-cytotoxic. The cytotoxicity of dental monomers has been evaluated by several investigators [19,33-35].

A previous in vitro study by Li et al. evaluated the effect of the alkyl chain length of DMAHDM in a series of antibacterial monomers on the cytotoxicity of human gingival fibroblasts and odontoblast-like cells. Their results showed that DMAHDM monomer on gingival fibroblasts had a cytotoxicity comparable to HEMA and TEGDMA monomers and lower than BisGMA [19].

According to the American Dental Association ADA specification No. 12 for denture base resin, second revision, acrylic denture resins should have adequate strength and resilience to resist the biting and chewing forces and adequate toughness and fracture resistance to maintain form and function for many years [36,37]. The flexural strength value for Lucitone 199 denture acrylic resin is $90 \mathrm{Mpa}$ and the flexural modulus value is 2510 Mpa [38].

In the present study, incorporating MPC into the Lucitone acrylic resin did not significantly influence the flexural strength; DMAHDM, however, produced flexural strength values that were lower than the minimum values accepted by the ADA Specification no.12 when added alone or in combination with MPC [36]. It has been previously documented in the literature that the modification of denture base materials through the addition of antimicrobial monomers can have a negative impact on the flexural strength of the material. In a study by Regis et al., methacryloyloxy undecyl pyridinium bromide (MUPB) was incorporated into a PMMA denture base material. The addition of MUPB significantly reduced the flexural strength of the denture base material, paralleling the results of this study [39]. Rodriguez et al. tested the effects of incorporating 2-tert-butylaminoethyl methacrylate (TBAEMA) into a denture base acrylic resin. Their results showed a similar pattern of flexural strength reduction after incorporations of TBAEMA, especially in concentrations higher than $1.75 \%$ [40]. Another study tested the mechanical and antifungal properties of a denture base resin containing phytoncide microcapsules (PTMCs), and the results showed that the flexural strength of the tested material decreased with increasing PTMC concentration. The flexural strength went from $97.58 \pm 4.79 \mathrm{MPa}$ for the control material to $53.66 \pm 2.46 \mathrm{MPa}$ for the experimental group containing 5.0\% PTMC [41]. 
The reduction in flexural strength due to the addition of DMAHDM may be an indication of insufficient mixing, which may result in formation of clusters of DMAHDM trapped within the material. These clusters may act as impurities, serving as areas of stress concentration. Future studies should employ improved mixing methods instead of manual mixing. For example, automatic mixing machines could eliminate mixing errors which could compromise the mechanical properties of the material.

The surface roughness of denture base materials is of special clinical relevance. Several studies have shown the correlation between denture surface roughness ( $\mathrm{Ra}$ ) and the colonization of $C$. albicans biofilms $[42,43]$. Rough denture surfaces provide a greater surface area for the adhesion of microbial biofilms when compared to polished surfaces. The results of this study showed that the addition of MPC and DMAHDM together or separately did not compromise the surface roughness of the material. In fact, the addition of the bioactive agents together seemed to improve the surface properties of the Lucitone acrylic resin. Previous studies have shown similar results, as the incorporation of $3 \%$ DMAHDM into different dental materials did not compromise the surface properties even after biofilm challenges [44-46]. Bajunaid et al. found that adding MPC at $4.5 \mathrm{wt} . \%$ resulted in significant fungal retardation and no effect on the surface roughness of the developed acrylic resin [11]. Another study by Balhaddad et al. evaluated the surface roughness of a composite material containing 5\% DMAHDM after $48 \mathrm{~h}$ biofilm formation, and the results showed no significant impact on surface roughness even after biofilm challenge [46].

Alternatively, natural polymers have been attempted as novel methods to enhance the antimicrobial properties of dental appliances. For example, polymethyl methacrylate (PMMA) was modified with chitosan, a natural polymer with antibacterial and antifungal properties $[47,48]$. Nawasrah et al. found that adding henna (Lawsonia inermis), an inexpensive natural extract that has antifungal propertie, to acrylic denture base material may control the proliferation of C. albicans [49]. Gad and colleagues, however, evaluated the effect of incorporating henna on the flexural strength of acrylic resin denture base material and found that the flexural strength was decreased significantly. This decrease was proportional to the concentration of henna added [50].

Neem powder (Azadirachta Indica) is another natural antimicrobial product that has been added to acrylic resin; its addition resulted in the formation of a composite that significantly decreased C. albicans adhesion [51].

Future studies should include multi-species biofilm models with more clinical relevance. In addition, the long-term antifungal effects of DMAHDM and MPC should be evaluated, along with their influence on the mechanical properties of the material after aging.

Author Contributions: Conceptualization, S.O.B., B.H.B. and H.H.K.X.; Data curation, S.O.B.; Formal analysis, S.O.B. and B.H.B.; Funding acquisition, H.H.K.X.; Investigation, S.O.B. and B.H.B.; Methodology, S.O.B. and B.H.B.; Project administration, M.D.W.; Resources, H.H.K.X. and M.D.W.; Supervision, H.H.K.X.; Validation, B.H.B. and M.D.W.; Writing—original draft, B.H.B.; Writing—review \& editing, S.O.B. All authors have read and agreed to the published version of the manuscript.

Funding: This research was funded by the Deanship of Scientific Research and the College of Dentistry Research Center at King Saud University, grant number (RG-1441-336). The APC was funded by the Deanship of Scientific Research at King Saud University.

Institutional Review Board Statement: Not applicable.

Informed Consent Statement: Not applicable.

Data Availability Statement: Date is available upon request.

Acknowledgments: Authors would like to acknowledge the Deanship of Scientific Research and the College of Dentistry Research Center at King Saud University for funding this research project.

Conflicts of Interest: Authors declare that there is no conflict of interest. 


\section{References}

1. Arweiler, N.B.; Netuschil, L. The oral microbiota. In Microbiota of the Human Body: Implications in Health and Disease, 1st ed.; Schwiertz, A., Ed.; Springer International Publishing: Heidelberg, Germany, 2016; pp. 45-60.

2. Coll, P.P.; Lindsay, A.; Meng, J.; Gopalakrishna, A.; Raghavendra, S.; Bysani, P.; O'Brien, D. The Prevention of Infections in Older Adults: Oral Health. J. Am. Geriatr. Soc. 2019, 68, 411-416. [CrossRef]

3. Patil, S.; Rao, R.S.; Majumdar, B.; Anil, S. Clinical Appearance of Oral Candida Infection and Therapeutic Strategies. Front. Microbiol. 2015, 6, 1391. [CrossRef]

4. Altarawneh, S.; Bencharit, S.; Mendoza, L.; Curran, A.; Barrow, D.; Barros, S.; Preisser, J.; Loewy, Z.G.; Gendreau, L.; Offenbacher, S. Clinical and histological findings of denture stomatitis as related to intraoral colonization patterns of Candida albicans, salivary flow, and dry mouth. J. Prosthodont. 2013, 22, 13-22. [CrossRef]

5. $\quad$ Bianchi, C.M.P.D.C.; Bianchi, H.A.; Tadano, T.; De Paula, C.R.; Hoffmann-Santos, H.D.; Leite, D.P.L.; Hahn, R.C. Factors related to oral candidiasis in elderly users and non-users of removable dental prostheses. Rev. Inst. Med. Trop. Sao Paulo 2016, 58, e17. [CrossRef]

6. $\quad$ Radford, D.R.; Sweet, S.P.; Challacombe, S.J.; Walter, J.D. Adherence of Candida albicans to denture-base materials with different surface finishes. J. Dent. 1998, 26, 577-583. [CrossRef]

7. Yarborough, A.; Cooper, L.; Duqum, I.; Mendonca, G.; McGraw, K.; Stoner, L. Evidence Regarding the Treatment of Denture Stomatitis. J. Prosthodont. 2016, 25, 288-301. [CrossRef] [PubMed]

8. Ikono, R.; Vibriani, A.; Wibowo, I.; Saputro, K.E.; Muliawan, W.; Bachtiar, B.M.; Mardliyati, E.; Bachtiar, E.W.; Rochman, N.T.; Kagami, H.; et al. Nanochitosan antimicrobial activity against Streptococcus mutans and Candida albicans dual-species biofilms. BMC Res. Notes 2019, 12, 383. [CrossRef]

9. Gheorghe, D.; Niculescu, A.-G.; Bîrcă, A.; Grumezescu, A. Biomaterials for the Prevention of Oral Candidiasis Development. Pharmaceutics 2021, 13, 803. [CrossRef] [PubMed]

10. Yodmongkol, S.; Chantarachindawong, R.; Thaweboon, S.; Thaweboon, B.; Amornsakchai, T.; Srikhirin, T. RC-TJ of prosthetic, 2014 undefined. The effects of silane-SiO 2 nanocomposite films on Candida albicans adhesion and the surface and physical properties of acrylic resin denture base material. J. Prosthet. Dent. 2014, 112, 1530-1538. [CrossRef] [PubMed]

11. Bajunaid, S.; Baras, B.; Balhaddad, A.; Weir, M.; Xu, H. Antibiofilm and Protein-Repellent Polymethylmethacrylate Denture Base Acrylic Resin for Treatment of Denture Stomatitis. Materials 2021, 14, 1067. [CrossRef]

12. Zhang, N.; Ma, J.; Melo, M.; Weir, M.D.; Bai, Y.; Xu, H.H. Protein-repellent and antibacterial dental composite to inhibit biofilms and caries. J. Dent. 2014, 43, 225-234. [CrossRef]

13. Zhang, N.; Weir, M.D.; Romberg, E.; Bai, Y.; Xu, H.H. Development of novel dental adhesive with double benefits of proteinrepellent and antibacterial capabilities. Dent. Mater. 2015, 31, 845-854. [CrossRef] [PubMed]

14. Wang, L.; Xie, X.; Li, C.; Liu, H.; Zhang, K.; Zhou, Y.; Chang, X.; Xu, H.H. Novel bioactive root canal sealer to inhibit endodontic multispecies biofilms with remineralizing calcium phosphate ions. J. Dent. 2017, 60, 25-35. [CrossRef]

15. Zhang, N.; Melo, M.A.S.; Antonucci, J.M.; Lin, N.J.; Lin-Gibson, S.; Bai, Y.; Xu, H.H. Novel Dental Cement to Combat Biofilms and Reduce Acids for Orthodontic Applications to Avoid Enamel Demineralization. Materials 2016, 9, 413. [CrossRef] [PubMed]

16. Baras, B.H.; Sun, J.; Melo, M.; Tay, F.; Oates, T.W.; Zhang, K.; Weir, M.D.; Xu, H.H. Novel root canal sealer with dimethylaminohexadecyl methacrylate, nano-silver and nano-calcium phosphate to kill bacteria inside root dentin and increase dentin hardness. Dent. Mater. 2019, 35, 1479-1489. [CrossRef] [PubMed]

17. Wang, L.; Xie, X.; Imazato, S.; Weir, M.D.; Reynolds, M.A.; Xu, H.H. A protein-repellent and antibacterial nanocomposite for Class-V restorations to inhibit periodontitis-related pathogens. Mater. Sci. Eng. C 2016, 67, 702-710. [CrossRef]

18. Zhou, H.; Li, F.; Weir, M.D.; Xu, H.H. Dental plaque microcosm response to bonding agents containing quaternary ammonium methacrylates with different chain lengths and charge densities. J. Dent. 2013, 41, 1122-1131. [CrossRef]

19. Li, F.; Weir, M.D.; Xu, H.H.K. Effects of quaternary ammonium chain length on antibacterial bonding agents. J. Dent. Res. 2013, 92, 932-938. [CrossRef]

20. Emami, E.; Kabawat, M.; Rompre, P.H.; Feine, J.S. Linking evidence to treatment for denture stomatitis: A meta-analysis of randomized controlled trials. J. Dent. 2014, 42, 99-106. [CrossRef]

21. Davenport, J.C. The oral distribution of candida in denture stomatitis. Br. Dent. J. 1970, 129, 151-156. [CrossRef]

22. Gendreau, L.; Loewy, Z.G. Epidemiology and Etiology of Denture Stomatitis. J. Prosthodont. 2011, 20, 251-260. [CrossRef] [PubMed]

23. Ramage, G.; Tomsett, K.; Wickes, B.; Lopez-Ribot, J.; Redding, S.W. Denture stomatitis: A role for Candida biofilms. Oral Surg. Oral Med. Oral Pathol. Oral Radiol. Endodontol. 2004, 98, 53-59. [CrossRef]

24. Mazur, M.; Duś-Ilnicka, I.; Jedliński, M.; Ndokaj, A.; Janiszewska-Olszowska, J.; Ardan, R.; Radwan-Oczko, M.; Guerra, F.; Luzzi, V.; Vozza, I.; et al. Facial and Oral Manifestations Following COVID-19 Vaccination: A Survey-Based Study and a First Perspective. Int. J. Environ. Res. Public Health 2021, 18, 4965. [CrossRef]

25. AbuBakr, N.; Salem, Z.; Kamel, A. Oral manifestations in mild-to-moderate cases of COVID-19 viral infection in the adult population. Dent. Med Probl. 2012, 58,7-15. [CrossRef]

26. Hori, K.; Matsumoto, S. Bacterial adhesion: From mechanism to control. Biochem. Eng. J. 2010, 48, 424-434. [CrossRef]

27. Katsikogianni, M.; Missirlis, Y. Concise review of mechanisms of bacterial adhesion to biomaterials and of techniques used in estimating bacteria-material interactions. Eur. Cells Mater. 2004, 8, 37-57. [CrossRef] [PubMed] 
28. Ishihara, K.; Ueda, T.; Nakabayashi, N. Preparation of Phospholipid Polylners and Their Properties as Polymer Hydrogel Membranes. Polym. J. 1990, 22, 355-360. [CrossRef]

29. Ishihara, K.; Nomura, H.; Mihara, T.; Kurita, K.; Iwasaki, Y.; Nakabayashi, N. Why do phospholipid polymers reduce protein adsorption? J. Biomed. Mater. Res. 1998, 39, 323-330. [CrossRef]

30. Cao, L.; Xie, X.; Wang, B.; Weir, M.D.; Oates, T.W.; Xu, H.H.; Zhang, N.; Bai, Y. Protein-repellent and antibacterial effects of a novel polymethyl methacrylate resin. J. Dent. 2018, 79, 39-45. [CrossRef]

31. Campos, K.D.P.L.; Viana, G.M.; Cabral, L.M.; Portela, M.B.; Junior, R.H.; Cavalcante, L.M.; Lourenco, E.J.V.; Telles, D.D.M. Self-cured resin modified by quaternary ammonium methacrylates and chlorhexidine: Cytotoxicity, antimicrobial, physical, and mechanical properties. Dent. Mater. 2019, 36, 68-75. [CrossRef]

32. Baras, B.H.; Wang, S.; Melo, M.; Tay, F.; Fouad, A.F.; Arola, D.D.; Weir, M.D.; Xu, H.H. Novel bioactive root canal sealer with antibiofilm and remineralization properties. J. Dent. 2019, 83, 67-76. [CrossRef] [PubMed]

33. Moharamzadeh, K.; Van Noort, R.; Brook, I.M.; Scutt, A.M. Cytotoxicity of resin monomers on human gingival fibroblasts and HaCaT keratinocytes. Dent. Mater. 2007, 23, 40-44. [CrossRef] [PubMed]

34. Huang, L.; Xiao, Y.-H.; Xing, X.-D.; Li, F.; Ma, S.; Qi, L.-L.; Chen, J.-H. Antibacterial activity and cytotoxicity of two novel cross-linking antibacterial monomers on oral pathogens. Arch. Oral Biol. 2011, 56, 367-373. [CrossRef]

35. Bhadila, G.; Wang, X.; Zhou, W.; Menon, D.; Melo, M.A.S.; Montaner, S.; Oates, T.W.; Weir, M.D.; Sun, J.; Xu, H.H. Novel low-shrinkage-stress nanocomposite with remineralization and antibacterial abilities to protect marginal enamel under biofilm. $J$. Dent. 2020, 99, 103406. [CrossRef]

36. Revised American Dental Association Specification No. 12 for denture base polymers. J. Am. Dent. Assoc. 1975, 90, 451-458. [CrossRef]

37. Gad, M.M.; Al-Thobity, A.M.; Fouda, S.M.; Näpänkangas, R.; Raustia, A. Flexural and Surface Properties of PMMA Denture Base Material Modified with Thymoquinone as an Antifungal Agent. J. Prosthodont. 2018, 29, 243-250. [CrossRef]

38. Dhir, G.; Berzins, D.W.; Dhuru, V.B.; Periathamby, A.R.; Dentino, A. Physical Properties of Denture Base Resins Potentially Resistant to Candida Adhesion. J. Prosthodont. 2007, 16, 465-472. [CrossRef]

39. Regis, R.R.; Zanini, A.P.; Della Vecchia, M.P.; Silva-Lovato, C.H.; Paranhos, H.D.F.O.; De Souza, R.F. Physical Properties of an Acrylic Resin after Incorporation of an Antimicrobial Monomer. J. Prosthodont. 2011, 20, 372-379. [CrossRef]

40. Rodriguez, L.S.; Paleari, A.G.; Giro, G.; Junior, N.M.D.O.; Pero, A.C.; Compagnoni, M.A. Chemical Characterization and Flexural Strength of a Denture Base Acrylic Resin with Monomer 2-Tert-Butylaminoethyl Methacrylate. J. Prosthodont. 2012, $22,292-297$. [CrossRef]

41. An, S.; Judge, R.B.; Wong, R.H.; Arzmi, M.H.; Palamara, J.E.; Dashper, S.G. Incorporation of the microencapsulated antimicrobial agent phytoncide into denture base resin. Aust. Dent. J. 2018, 63, 302-311. [CrossRef] [PubMed]

42. Radford, D.R.; Watson, T.F.; Walter, J.D.; Challacombe, S.J. The effects of surface machining on heat cured acrylic resin and two soft denture base materials: A scanning electron microscope and confocal microscope evaluation. J. Prosthet. Dent. 1997, 78, 200-208. [CrossRef]

43. Consani, R.L.X.; Folli, B.L.; Nogueira, M.C.F.; Correr, A.B.; Mesquita, M.F. Effect of Polymerization Cycles on Gloss, Roughness, Hardness and Impact Strength of Acrylic Resins. Braz. Dent. J. 2016, 27, 176-180. [CrossRef]

44. Wang, L.; Xie, X.; Qi, M.; Weir, M.D.; Reynolds, M.A.; Li, C.; Zhou, C.; Xu, H.H. Effects of single species versus multispecies periodontal biofilms on the antibacterial efficacy of a novel bioactive Class-V nanocomposite. Dent. Mater. 2019, 35, 847-861. [CrossRef]

45. Bhadila, G.; Baras, B.H.; Weir, M.D.; Wang, H.; Melo, M.A.S.; Hack, G.D.; Bai, Y.; Xu, H.H.K. Novel antibacterial calcium phosphate nanocomposite with long-term ion recharge and re-release to inhibit caries. Dent. Mater. J. 2020, 39, 678-689. [CrossRef] [PubMed]

46. Balhaddad, A.A.; Ibrahim, M.S.; Weir, M.D.; Xu, H.H.; Melo, M.A.S. Concentration dependence of quaternary ammonium monomer on the design of high-performance bioactive composite for root caries restorations. Dent. Mater. 2020, 36, e266-e278. [CrossRef] [PubMed]

47. Walczak, K.; Schierz, G.; Basche, S.; Petto, C.; Boening, K.; Wieckiewicz, M. Antifungal and Surface Properties of Chitosan-Salts Modified PMMA Denture Base Material. Molecules 2020, 25, 5899. [CrossRef] [PubMed]

48. Paradowska-Stolarz, A.; Wieckiewicz, M.; Owczarek, A.; Wezgowiec, J. Natural Polymers for the Maintenance of Oral Health: Review of Recent Advances and Perspectives. Int. J. Mol. Sci. 2021, 22, 10337. [CrossRef]

49. Nawasrah, A.; AlNimr, A.; Ali, A.A. Antifungal Effect of Henna against Candida albicans Adhered to Acrylic Resin as a Possible Method for Prevention of Denture Stomatitis. Int. J. Environ. Res. Public Health 2016, 13, 520. [CrossRef]

50. Gad, M.; Rahoma, A.; Nawasra, A.; Ammar, M. Influence of Henna Addition on The Flexural Strength of Acrylic Denture Base Material: An In Vitro Study. Al-Azhar Dent. J. Girls 2018, 5, 277-283. [CrossRef]

51. Hamid, S.-K.; Al-Dubayan, A.-H.; Al-Awami, H.; Khan, S.; Gad, M.-M. In vitro assessment of the antifungal effects of neem powder added to polymethyl methacrylate denture base material. J. Clin. Exp. Dent. 2019, 11, e170-e178. [CrossRef] 